\title{
Frequency of anemia and micronutrient deficiency among children with cleft lip and palate: a single- center cross-sectional study from Uttarakhand, India
}

Debarati Chattopadhyay ${ }^{1}$, Madhubari Vathulya ${ }^{1}$, Manisha Naithani², Praveen A Jayaprakash ${ }^{1}$, Sarika Palepu ${ }^{3}$, Arkapal Bandyopadhyay ${ }^{4}$, Akshay Kapoor ${ }^{1}$, Uttam Kumar Nath ${ }^{5}$

Departments of ${ }^{1}$ Burns and Plastic Surgery and ${ }^{2}$ Biochemistry, All India Institute of Medical Sciences, Rishikesh; ${ }^{3}$ Department of Community Medicine, Government Medical College, Srinagar; Departments of ${ }^{4}$ Pharmacology and ${ }^{5}$ Medical Oncology Hematology, All India Institute of Medical Sciences, Rishikesh, India
Background: Children with cleft lip and/or palate can be undernourished due to feeding difficulties after birth. A vicious cycle ensues where malnutrition and low body weight precludes the child from having the corrective surgery, in the absence of which the child fails to gain weight. This study aimed to identify the proportion of malnutrition, including the deficiency of major micronutrients, namely iron, folate and vitamin $\mathrm{B}_{12}$, in children with cleft lip and/or palate and thus help in finding out what nutritional interventions can improve the scenario for these children.

Methods: All children less than 5 years with cleft lip and/or cleft palate attending our institute were included. On their first visit, following were recorded: demographic data, assessment of malnutrition, investigations: complete blood count and peripheral blood film examination; serum albumin, ferritin, iron, folate, and vitamin $\mathrm{B}_{12}$ levels.

Results: Eighty-one children with cleft lip and/or palate were included. Mean age was $25.37 \pm 21.49$ months (range, 3-60 months). In 53\% of children suffered from moderate to severe wasting, according to World Health Organization (WHO) classification. Iron deficiency state was found in $91.6 \%$ of children. In $35.80 \%$ of children had vitamin $B_{12}$ deficiency and $23.45 \%$ had folate deficiency. No correlation was found between iron deficiency and the type of deformity. Conclusion: Iron deficiency state is almost universally present in children with cleft lip and palate. Thus, iron and folic acid supplementation should be given at first contact to improve iron reserve and hematological parameters for optimum and safe surgery.

Keywords: Anemia / Cleft lip / Cleft palate / Iron deficiency

\section{INTRODUCTION}

Cleft lip and/or palate is one of the most common congenital anomalies throughout the world. The worldwide incidence of

Correspondence: Debarati Chattopadhyay

Department of Burns and Plastic Surgery, All India Institute of Medical Sciences, Rishikesh 249201, Uttarakhand, India

E-mail: debarati1981@gmail.com

The study was funded by Mission Smile AIIMS Rishikesh scheme. This article was presented at APSICON 2019, Bhubaneswar, India.

Received August 21, 2020 / Revised December 28, 2020 / Accepted February 15, 2021 cleft lip and/or palate is 1:600 [1]. Although the Birth Defects Registry of India was established in 2001, sufficient data is still lacking, and the incidence of clefts in the Indian population is not precisely known [2]. However, between 28,000 to 35,000 children are born with clefts in India each year. It implies about 1 out of every 500 to 800 live births is a patient with cleft lip and/or palate [3]. These are complex anomalies that involve the nose, lips, alveolus, or palate and cause problems in breathing, appearance, dentition, dental occlusion, facial growth, speech, and hearing. 
These children can be undernourished due to feeding difficulties after birth. The feeding difficulties result from the inability to consume enough nutrients during the first months of life due to inadequate oral competence and infectious processes in the upper airways or middle ear.

These children are thus highly susceptible to micronutrient deficiencies. The vicious cycle of malnutrition and low body weight precludes the child from having the corrective surgery, in the absence of which the child fails to gain weight. The present study was conducted in our institute to identify the proportion of malnutrition, including the deficiency of major micronutrients, in children with cleft lip and/or palate. The purpose is to suggest additional nutritional interventions over existing national recommendations to improve the well-being of these children.

The study aimed to assess the proportion of malnutrition and micronutrient deficiency in children with primary cleft lip and/ or palate below 5 years attending our institute. Specific objectives of the study were: (1) to assess the status of malnutrition by anthropometry; (2) to assess the status of iron, ferritin, folate, and vitamin B12, and magnitude of iron deficiency anemia in children with cleft lip and/or palate; or (3)correlate the presence of nutritional deficiency with the type of deformity.

\section{METHODS}

This study was conducted at All India Institute of Medical Sciences (AIIMS) Rishikesh which is a tertiary care center in Uttarakhand, India between March 2017 to September 2019. It was a cross-sectional study approved by the institutional ethics committee. All children with primary cleft lip and/or palate less than 5 years of age were included in the study. Children with syndromes or with secondary deformities were excluded. At the first visit, demographic data like age, sex, weight, length, breastfeeding history, and socioeconomic status were recorded. Height/ length and weight were plotted on the World Health Organization (WHO) Z score charts. Investigations performed were complete hemogram, peripheral smear, serum albumin, serum iron, serum ferritin, serum folate, and vitamin $B_{12}$ levels.

Corrective surgery for the patients was scheduled at 3 months to 6 months for cleft lip, and 6 months to 9 months for cleft palate. For patients who presented late, corrective surgery was performed as soon as possible. Complete data could be recorded in 81 patients.

Complete hemogram was done by an automated hematology analyzer (Sysmex XN-1000; Kobe, Japan). Serum ferritin, vita$\min \mathrm{B}_{12}$, and folate levels were done by Chemiluminescence assay. Anemia was classified as mild (10.0-10.9 g/dL), moderate (7.0-9.9 g/dL) and severe $(<7.0 \mathrm{~g} / \mathrm{dL})$ [4]. Serum ferritin levels below $12 \mathrm{ng} / \mathrm{ml}$ were labelled as low ferritin levels [5].

The data collected was then tabulated and analyzed. Ninety patients who presented for some reconstructive surgery belonging to the same age group were taken as controls. Statistical analysis was done using SPSS version 20 (IBM Corp., Armonk, NY, USA). Demographic data like age, sex, etc., were represented as mean \pm standard deviation. A Student $t$-test was done to compare the hemoglobin levels, serum ferritin, vitamin $B_{12}$, and folate levels.

\section{RESULTS}

A total of 81 patients with cleft lip and/or palate were included in the present study. Gender distribution showed that $42 \mathrm{pa}-$ tients (51.85\%) were females and 39 patients (48.15\%) were males. The mean age of the study group was $25.37 \pm 21.49$ months. Age categorization of the study group showed that 42 patients (51.8\%) were infants ( $<1$ year), 13 (16\%) were between 1-3 years, and 26 (32.2\%) were between 3-5 years of age. Out of these, 37 patients had isolated cleft lip, 32 patients had isolated cleft palate, and the remaining 12 had combined cleft lip and palate. None of the patients were breastfed, but all of them received expressed breast milk through paladai or spoon. All of them also received supplementary formula feeds. The control group had 90 children, of which 46 were females, and 44 were males. The mean age of the control group was $22.94 \pm 15.69$ months (Table 1).

A comparison of the weight between cleft and control groups at different ages were made. In all the age groups, i.e., less than 1 year, $1-3$ years, and $3-5$ years, the children in the cleft group had lower mean body weights compared to that of the control group, and the difference was statistically significant $(p=0.005$, $p=0.008$, and $p=0.004$, respectively) (Table 2 ).

Malnutrition was assessed using $\mathrm{WHO}$ standards, and the $\mathrm{Z}$ score was calculated. Out of the 81 patients, 41 (50.61\%) had moderate wasting, and three (3.7\%) had severe wasting (Table 3). On the other hand, in the control group, only $23.3 \%$ (21) had moderate wasting, and none had severe wasting.

In the study group, 21 patients (25.92\%) had hemoglobin lev-

Table 1. Demographics of patients in study and control groups

\begin{tabular}{lcc}
\hline Patient & Cleft group & Control group \\
\hline No. of patients & 81 & 90 \\
Sex & & \\
$\quad$ Male & 39 & 44 \\
Female & 42 & 46 \\
Age (mo) & $25.37 \pm 21.49$ & $22.94 \pm 15.69$ \\
\hline
\end{tabular}

Values are presented as number or mean \pm SD. 
Table 2. Comparison of weight between cleft and control group in different age groups

\begin{tabular}{llccc}
\hline Age & Group & No. & Mean weight $(\mathrm{kg})$ & $p$-value \\
\hline$<1$ Year & Cleft & 42 & 5.943 & 0.005 \\
& Control & 45 & 7.818 & \\
\multirow{2}{*}{ to $<$ 3 Years } & Cleft & 13 & 9.138 & 0.008 \\
& Control & 16 & 12.354 & \\
3 3 to 5 Years & Cleft & 26 & 13.829 & 0.004 \\
& Control & 29 & 18.446 & \\
\hline
\end{tabular}

els $>11 \mathrm{~g} / \mathrm{dL}$. Thirty-five patients (43.20\%) had mild anemia,18 patients (22.22\%) had moderate anemia, and seven patients (8.64\%) had severe anemia. Overall, $74.06 \%$ of patients were anemic. In the control group, only $60 \%$ of the patients had hemoglobin levels below $11 \mathrm{~g} / \mathrm{dL}$. The difference between the mean hemoglobin levels of the study group and the control group was not statistically significant $(p=0.83)$. Out of $42 \mathrm{fe}-$ males in the study group, 38 (90.4\%) had iron deficiency (serum iron $<60 \mu \mathrm{g} / \mathrm{dL}$ ), and out of 39 males in the study group, 36 (92.3\%) had iron deficiency. Overall, $91.6 \%$ of the patients in the study population had low serum iron levels. Whereas in the control group, only $63.3 \%$ of the patients had low serum iron levels. Mean serum iron levels in the control group were $57.73 \pm 14.7 \mu \mathrm{g} / \mathrm{dL}$, whereas mean serum iron levels in the study group were $42.28 \pm 12.64 \mu \mathrm{g} / \mathrm{dL}$, and this difference in serum iron levels were statistically significant $(p=0.001)$. Seventy-one patients (88.89\%) in the study group had serum ferritin levels $<12 \mu \mathrm{g} / \mathrm{L}$. Mean serum ferritin levels in the study group were $10.84 \pm 1.64 \mu \mathrm{g} / \mathrm{L}$, and the control group was $13.06 \pm 3.07 \mu \mathrm{g} / \mathrm{L}$. This difference was also statistically significant $(p=0.001)$. Hence iron deficiency state with/without anemia was almost universally present in all the children with cleft lip and/or palate. The iron deficiency state was significantly higher compared to that of age-matched controls of the same population. The iron deficiency state had no relation to the type of deformity present.

Nineteen patients (23.45\%) in the study group had folate deficiency. Mean serum folate levels in the study group were 15.96 $\pm 8.64 \mathrm{ng} / \mathrm{mL}$ and in the control group was $12.39 \pm 7.22 \mathrm{ng} / \mathrm{mL}$. This difference was statistically significant $(p=0.009)$. Twentynine patients (35.80\%) had vitamin $\mathrm{B}_{12}$ deficiency in the study group. Mean serum vitamin $B_{12}$ level in the study group was $197.7 \pm 49.41 \mathrm{ng} / \mathrm{mL}$ and in the control group was $202.97 \pm$ $28.25 \mathrm{ng} / \mathrm{mL}$. This difference was statistically significant $(p=$ 0.04 ). Out of the 81 patients in this study, 12 patients had combined cleft lip and palate. All 12 of these patients had vitamin $B_{12}$ deficiency (100\%). Ten out of 12 patients had folate deficiency (83.33\%) (Table 4).

The micronutrient deficiencies were also compared across the
Table 3. Comparison of Z score

\begin{tabular}{lccc}
\hline Weight for height (Z score) & $\begin{array}{c}\text { Frequency } \\
\text { in boys } \\
(n=39)\end{array}$ & $\begin{array}{c}\text { Frequency } \\
\text { in girls } \\
(n=42)\end{array}$ & $\begin{array}{c}\text { Total } \\
(n=81)\end{array}$ \\
\hline No wasting $(>-2$ SD) & 23 & 14 & 37 \\
Moderate wasting (-2 SD to $\leq-3$ SD) & 15 & 26 & 41 \\
Severe wasting (> -3 SD) & 1 & 2 & 3 \\
\hline
\end{tabular}

$\mathrm{SD}$, standard deviation.

Table 4. Comparison of hemoglobin and micronutrient levels between the study and the control groups

\begin{tabular}{lccl}
\hline \multirow{2}{*}{ Variable } & \multicolumn{2}{c}{ Mean \pm SD } & \multirow{2}{*}{$p$-value } \\
\cline { 2 - 3 } & \multicolumn{1}{c}{ Cleft group } & Control group & \\
\hline Hemoglobin $(\mathrm{g} / \mathrm{dL})$ & $10.83 \pm 6.01$ & $10.66 \pm 1.91$ & 0.83 \\
Serum iron $(\mu \mathrm{g} / \mathrm{dL})$ & $42.80 \pm 11.67$ & $53.67 \pm 10.02$ & 0.001 \\
Serum ferritin $(\mu \mathrm{g} / \mathrm{dL})$ & $10.84 \pm 1.64$ & $13.06 \pm 3.07$ & 0.001 \\
Serum folate $(\mathrm{ng} / \mathrm{mL})$ & $15.96 \pm 8.64$ & $12.39 \pm 7.22$ & 0.009 \\
Serum vitamin $\mathrm{B}_{12}(\mathrm{ng} / \mathrm{mL})$ & $197.7 \pm 49.41$ & $202.97 \pm 28.25$ & 0.04 \\
\hline
\end{tabular}

different age groups in the study. Comparison of the hemoglobin levels in different age groups showed that the children in the older age group had the highest mean hemoglobin level of $11.47 \pm 2.14 \mathrm{~g} / \mathrm{dL}$, and children in the age group of less than 1 year had the lowest mean hemoglobin level of $10.15 \pm 1.40 \mathrm{~g} / \mathrm{dL}$. This difference was statistically significant $(p=0.006)$. The serum iron and ferritin levels also showed the same pattern, with children in the age group of 3-5 years having the higher serum levels of iron and ferritin, and with children in the age group of less than 1 year having the lowest serum iron and ferritin levels. These differences in serum levels of iron and ferritin were statistically significant ( $p=0.044$ and $p=0.033$, respectively) (Table 5).

\section{DISCUSSION}

Cleft lip and/or palate is one of the most common but significantly disfiguring congenital anomalies affecting children [6]. Children with cleft lip and/or palate are more prone to malnutrition compared to other children of their own age. Such malnutrition results from the feeding difficulties after birth, which occur due to the deformity itself that precludes the child from generating sufficient intraoral suction pressure or from frequent respiratory and ear infections [7]. The prevalence of malnutrition among infants with cleft lip and/or palate in the literature varies between $30 \%$ and $50 \%[8,9]$. However, information on the prevalence of malnutrition among such infants in India is rare.

In our study, $53.08 \%$ of patients had moderate to severe wasting, according to WHO classification [10]. The prevalence of wasting in the present study is much higher than the national average of $21 \%$ and Uttarakhand state's average of $34 \%$ accord- 
Table 5. Comparison of hemoglobin and micronutrient levels across different age groups in the study population

\begin{tabular}{lcccc}
\hline Variable & \multicolumn{3}{c}{ Age, mean \pm SD } & $p$ p-value \\
\cline { 2 - 4 } & \multicolumn{1}{c}{$<$ Year } & 1 to $<3$ Years & 3 to 5 Years & 0.006 \\
Hemoglobin $(\mathrm{g} / \mathrm{dL})$ & $10.15 \pm 1.40$ & $10.22 \pm 1.18$ & $11.47 \pm 2.14$ & 0.044 \\
Iron $(\mu \mathrm{g} / \mathrm{dL})$ & $40.13 \pm 11.39$ & $42.31 \pm 11.89$ & $47.35 \pm 11.02$ & 0.033 \\
Ferritin $(\mu \mathrm{g} / \mathrm{dL})$ & $10.35 \pm 0.55$ & $10.78 \pm 1.01$ & $11.62 \pm 2.55$ & 0.189 \\
Folic acid $(\mathrm{ng} / \mathrm{mL})$ & $14.24 \pm 8.17$ & $17.46 \pm 8.36$ & $17.92 \pm 9.26$ & 0.051 \\
Vitamin $B_{12}(\mathrm{ng} / \mathrm{mL})$ & $187.61 \pm 47.99$ & $191.06 \pm 40.43$ & $216.94 \pm 51.70$ & \\
\hline
\end{tabular}

ing to NFHS-4 [11]. Another study conducted in 723 districts of India showed that wasting ranged from $5.5 \%$ to $30 \%$ with a prevalence of $15.7 \%$ [12]. This data strengthens the general observation that children with cleft lip and/or palate suffer from malnutrition.

Anemia, in turn, is a condition that impacts development. Iron deficiency with or without anemia in the first 6 months of life can lead to a deficiency in a child's physical and cognitive development. The afflicted child is likely to remain vulnerable to infection and has lower immunity [13]. Anemia also adversely affects wound healing.

The prevalence of anemia in our study $(74.6 \%)$ is higher than the national average of $58.6 \%$, tabulated by NFHS 4 [11]. The majority of the data on anemia comes from studies on young school-going children. Minimal data is available on children with cleft lip and/or palate already in a compromised state because of poor feeding. The study of Dvivedi et al. (2012) in the hilly Himalayan region showed the prevalence of anemia as $83.16 \%$ in patients with cleft lip and/or palate [14]. The prevalence is higher in comparison to our study as patients from all age groups were included, and only $59.6 \%$ of patients were less than 5 years old. Similarly, the incidence of anemia was reported to be $89.9 \%$ in a study by Singhal et al. [15] in the year 2014 .

This improvement over the last 6 years may have been because of the improved awareness about this condition among the general population and various measures are taken through the state-sponsored and NGO (non-governmental organization) programs.

What is more concerning is, that iron deficiency state was found in more than $90 \%$ of the children with cleft lip and/or palate, irrespective of the type of deformity. Iron deficiency state was significantly more than in age-matched controls. Iron deficiency state may be present despite normal hemoglobin and blood count. It signifies a low amount of stored iron in the body.

Persistent infection or blood loss can lead to the development of overt anemia in such patients [16]. This explained our previous clinical findings that when the children with apparently normal hemoglobin during cleft lip surgery returned 6 months later for palatoplasty, hemoglobin levels were invariably low. This resulted in a delay in palatoplasty and increased transfusion requirements.

Hemoglobin level is not a reliable indicator of iron deficiency state; serum ferritin is considered the indicator of choice to evaluate the same [17]. In our study, reduced ferritin level was seen in $88.7 \%$ of patients. This is an alarming concern as they might progress to overt iron deficiency anemia in the future. Since no data on ferritin levels in cleft patients are present in published literature, our study remains first of its kind.

The National Nutritional Anemia Control Program (1991) in India provides iron supplements to children older than 12 months [13]. It is long recognized that infants with low birth weight need additional iron from about 2 months of age to build iron stores and meet their rapid growth requirements. Infants not on exclusive breastfeeding may also need small amounts of additional iron to compensate for the iron they do not receive through breast milk [18]. Children with cleft lip and/or palate fall in either of these categories as they usually have low birth weight, failure to thrive, and poor breastfeeding rates. However, since there is no standard policy for iron supplementation for younger children, they do not receive such from the health centers where health care professionals first see them.

In the above circumstances, we suggest that iron supplementation be started in children with cleft lip and/or palate at first contact by health workers. This simple step can go a long way in improving micronutrient deficiency, control of infections, and optimizing hematological parameters for the face changing and life-changing surgery in these children.

In conclusion, anemia is commonly seen in children with cleft lip and/or palate. Iron deficiency is the most common cause of anemia in children with cleft lip and/or palate. Folate and vitamin $B_{12}$ deficiency are more common in children with both cleft lip and palate, compared to children having only one of the two deformities. Hence iron and folic acid supplementation should be given at first contact to improve iron reserve and hematological parameters for optimum and safe surgery. 


\section{NOTES}

\section{Conflict of interest}

No potential conflict of interest relevant to this article was reported.

\section{Ethical approval}

The study was approved by the Institutional Review Board of AIIMS Rishikesh (IRB No. AIIMS/IEC/17/135) and performed in accordance with the principles of the Declaration of Helsinki. Written informed consent was obtained from the parents of the children.

\section{ORCID}

Debarati Chattopadhyay https://orcid.org/0000-0002-0167-7561 Madhubari Vathulya https://orcid.org/0000-0002-7050-5990 Manisha Naithani https://orcid.org/0000-0002-0984-4176 Praveen A Jayaprakash https://orcid.org/0000-0001-8486-5551 Sarika Palepu https://orcid.org/0000-0001-6534-2149 Arkapal Bandyopadhyay

https://orcid.org/0000-0001-9755-0233

Akshay Kapoor https://orcid.org/0000-0003-4223-9039

Uttam Kumar Nath https://orcid.org/0000-0001-7762-803X

\section{Author contribution}

Conceptualization: UKN. Methodology: DC, UKN. Formal analysis: PAJ, AB, SP. Funding acquisition: DC. Project administration: DC, MV, MN. Visualization: DC, UKN. Writing original draft: DC, AK. Writing - review and editing: DC, AK, PAJ. Approval of final manuscript: all authors.

\section{REFERENCES}

1. Mossey P, Little J. Addressing the challenges of cleft lip and palate research in India. Indian J Plast Surg 2009;42 Suppl:S9-18.

2. Sharma R. Birth defects in India: hidden truth, need for urgent attention. Indian J Hum Genet 2013;19:125-9.

3. Reddy SG, Reddy LV, Reddy RR. Developing and standardizing a center to treat cleft and craniofacial anomalies in a developing country like India. J Craniofac Surg 2009;20(Suppl2): 1664-7.

4. International Institute for Population Science. National Family Health Survey (NFHS-3), 2005-06 [Internet]. Mumbai: International Institute for Population Science; c2006 [cited 2021 Feb 15]. Available from: http://rchiips.org/nfhs/nfhs3.shtml

5. Ahmad MS, Farooq H, Maham SN, Qayyum Z, Waheed A, Nasir W. Frequency of anemia and iron deficiency among chil- dren starting first year of school life and their association with weight and height. Anemia 2018;2018:8906258.

6. Stewart BT, Carlson L, Hatcher KW, Sengupta A, Vander Burg R. Estimate of unmet need for cleft lip and/or palate surgery in India. JAMA Facial Plast Surg 2016;18:354-61.

7. Reid J. A review of feeding interventions for infants with cleft palate. Cleft Palate Craniofac J 2004;41:268-78.

8. Montagnoli LC, Barbieri MA, Bettiol H, Marques IL, de Souza L. Growth impairment of children with different types of lip and palate clefts in the first 2 years of life: a cross-sectional study. J Pediatr (Rio J) 2005;81:461-5.

9. Pandya AN, Boorman JG. Failure to thrive in babies with cleft lip and palate. Br J Plast Surg 2001;54:471-5.

10. Seetharaman N, Chacko TV, Shankar SLR, Mathew AC. Measuring malnutrition-the role of $\mathrm{Z}$ scores and the composite index of anthropometric failure (CIAF). Indian J Community Med 2007;32:35-9.

11. International Institute for Population Science. National Family Health Survey (NFHS-4), 2015-16 [Internet]. Mumbai: International Institute for Population Science; c2017 [cited 2021 Feb 15]. Available from: http://rchiips.org/nfhs/NFHS-4Reports/ India.pdf.

12. India State-Level Disease Burden Initiative CGF Collaborators. Mapping of variations in child stunting, wasting and underweight within the states of India: the Global Burden of Disease Study 2000-2017. EClinicalMedicine 2020;22:100317.

13. Kotecha PV. Nutritional anemia in young children with focus on Asia and India. Indian J Community Med 2011;36:8-16.

14. Dvivedi J, Dvivedi S. A clinical and demographic profile of the cleft lip and palate in sub-Himalayan India: a hospital-based study. Indian J Plast Surg 2012;45:115-20.

15. Singhal S, Negi G, Chandra H, Chandra S, Gaur DS, Rajan M. Hematological parameters in patients of cleft lip and cleft palate with special reference to eosinophil counts. J Craniofac Surg 2014;25:103-5.

16. United Nations Children's Fund; United Nations University; World Health Organization (WHO). Iron deficiency anaemia: assessment, prevention, and control: a guide for programme managers. Geneva: WHO; 2001.

17. World Health Organization (WHO). Assessing the iron status of populations: report of a joint World Health Organization/ Centers for Disease Control and Prevention technical consultation on the assessment of iron status at the population level. 2nd ed. Geneva: WHO; 2004.

18. Sahu SK, Kumar SG, Bhat BV, Premarajan KC, Sarkar S, Roy G, et al. Malnutrition among under-five children in India and strategies for control. J Nat Sci Biol Med 2015;6:18-23. 